\title{
Association Between Happiness and Objective/Subjective Economic Status Among Older Adults in Myanmar
}

\section{Yuri Sasaki ( $\sim$ sasakiy1006@gmail.com )}

National Institute of Public Health https://orcid.org/0000-0002-5832-7001

\section{Yugo Shobugawa}

Niigata University Graduate School of Medical and dental Sciences

\section{Ikuma Nozaki}

National Center for Global Health and Medicine: Kokuritsu Kenkyu Kaihatsu Hojin Kokuritsu Kokusai

Iryo Kenkyu Center

\section{Daisuke Takagi}

Graduate School of Medicine, the University of Tokyo

\section{Yuiko Nagamine}

Tokyo Medical and Dental University: Tokyo Ika Shika Daigaku

\section{Masafumi Funato}

Harvard University T H Chan School of Public Health

\section{Yuki Chihara}

Niigata University Graduate School of Medical and Dental Sciences

\section{Yuki Shirakura}

Niigata University Graduate School of Medical and Dental Sciences

\section{Kay Thi Lwin}

University of Medicine I

\section{Poe Ei Zin}

University of Medicine I

\section{Thae Zarchi Bo}

University of Medicine I

\section{Tomofumi Sone}

National Institute of Public Health

\section{Hla Hla Win}

University of Public Health, Yangon

\section{Research article}

Keywords: happiness, objective economic status, subjective economic status, older adults, Myanmar 
Posted Date: December 8th, 2020

DOI: https://doi.org/10.21203/rs.3.rs-122513/v1

License: (c) (i) This work is licensed under a Creative Commons Attribution 4.0 International License. Read Full License 


\section{Abstract}

\section{Background}

Few studies have examined whether objective or subjective economic status (ES) has a greater effect on the happiness of older adults in developing countries with ageing populations. This study examined whether objective/subjective economic status (ES) is associated with happiness in older adults in Myanmar.

\section{Method}

A multistage, random sampling procedure and face-to-face interviews were conducted in urban and rural areas in Myanmar. The happiness of 1,200 participants aged 60+ was evaluated using a single happiness score of 0 (very unhappy) to 10 (very happy). The wealth index, used as an objective economic indicator, was calculated from household asset items. Subjective economic status was assessed by asking "Which of the following best describes your current financial situation in light of general economic conditions?" The possible responses ranged from (1) very difficult to (5) very comfortable.

\section{Results}

The mean happiness score was lower among participants with low objective and subjective ES than among those with medium or high objective ES (6.24 versus 6.80 points, $p<0.001)$ and average or higher subjective ES (5.62 versus 6.83 points, $p<0.001$ ), respectively. Both low objective and subjective ES were negatively associated with happiness after adjusting for confounding variables (B: $-0.41,95 \%$ confidence interval [Cl]: $-0.69,-0.13$ and $\mathrm{B}:-0.71,95 \% \mathrm{Cl}:-1.00,-0.42$, respectively) and stratification by region (low objective ES, urban: $\mathrm{B}:-0.52,95 \% \mathrm{Cl}-1.03,-0.02$; low subjective ES, urban: $\mathrm{B}:-0.50,95 \% \mathrm{Cl}:-0.96,-0.03$; low objective ES, rural: $\mathrm{B}:-0.37,95 \% \mathrm{Cl}:-0.73,-0.02$; and low subjective $\mathrm{ES}$, rural: $\mathrm{B}:-0.80,95 \% \mathrm{Cl}:-1.18$, $-0.41)$.

\section{Conclusions}

In Myanmar, both objective and subjective ES might influence happiness among older adults. Although they had a similar impact on happiness in urban areas, subjective ES had a stronger impact in rural areas. Interventions for promoting happiness in older adults should consider differences in how objective/subjective ES impacts happiness in different regions, and focus should be placed not only on improving objective ES but also subjective ES in society.

\section{Introduction}

There is growing interest in the role that well-being plays in improving a population's health. The European Commission argued that current measures of economic performance, such as gross domestic product, are insufficient as indicators of a society's progress, and that personal well-being should also be 
taken into account[1, 2]. It has also been argued that psychological well-being should be addressed in measures of health valuation, and be considered in health care resource allocation $[1,3]$.

Happiness, defined as "the overall appreciation of one's life-as-a-whole," is a key marker of psychological well-being[4] and is closely related to health[1]. Many studies have reported that happiness is associated with better health outcomes, such as lower mortality, reduced morbidity, and functional independence in both community-dwelling and clinical populations [5-11]. The link between happiness and health may become more important as one ages, as the prevalence of chronic illness increases with age[1].

A number of physiological mechanisms might explain these findings[12]. Happiness appears to be inversely related to perceived stress[13] and may protect against illness through improved immune responses[4]. Happy people typically enjoy better health outcomes because they demonstrate more successful adaptation; better problem-solving skills and coping strategies; more creative, imaginative, and integrative thinking; greater resilience; and a stronger ability to deal with adversity $[8,14,15]$.

Identifying the determinants of happiness is not only important for improving personal well-being, but also for gaining insight into the factors that affect health and longevity. The recognition of these determinants may lead to elevated health status, increased life expectancy, and lower medical expenses [16]. Previous studies have reported that happiness is associated with having high self-perceived health[15, 17], health insurance coverage[18, 19], social support[15], living partners[15, 20-22] (or not living alone)[23], and lower stress[21]; the male gender[15, 24]; longevity[1, 12, 24]; the absence of depression[23]; and smoking history[24].

Objective economic status (ES) is also known to be correlated with happiness. For example, people with high ES as measured by objective indicators such as household income are more likely to be happier than people with low ES [15-17, 20-22, 25-27]. There are also suggestions that subjective ES (i.e., perceptions of having higher ES or better financial status) is of importance [26, 28-30]. For example, a study in five sub-Saharan countries showed that people who were moderately to completely satisfied with their financial situation were significantly more likely to report richer health and happiness relative to those who were completely dissatisfied [29]. However, to our knowledge, few studies have examined whether objective or subjective ES has a greater effect on the happiness of older adults, despite concerns about the growing economic cost of morbidity and functional dependence of older adults in developing countries with ageing populations[31].

In Myanmar, the proportion of the population aged $\geq 60$ years will almost double to $15 \%$ between 2010 and 2030 and is projected to reach $25 \%$ of the overall population by 2050[32]. The implications of the increasing rate of functional dependence in Myanmar are expected to be significant, as effective medical care systems are still in the developmental stages after a long period of military control between 1962 and $2011[33,34]$. In such a situation, it is important to examine the factors affecting happiness, which has been reported to buffer the risk of morbidity and functional dependence among older adults in Myanmar. 


\section{Methods}

\section{Aim}

The aim of this study was to examine whether objective/subjective ES is associated with happiness in older adults in Myanmar.

\section{Study design and participants}

This was a baseline survey of the 2018 longitudinal study "Healthy and Active Aging in Myanmar," which examined the predictors of physical and psychological health in community-dwelling Myanmar adults aged $\geq 60$ years.

The field sites were the Yangon region and the Bago region, which is located 91 kilometers north-east of Yangon. Multistage random sampling was conducted in the two regions. There are 45 townships in the Yangon region and 28 in the Bago region. First, six townships were randomly selected from each region via population proportional sampling based on the population of each township. Next, in Yangon, 10 wards were further randomly selected from each township, while in Bago, 10 village tracts were selected from each township again based on the population of each township/village tract. Finally, 10 people were randomly selected from each extracted ward/village tract using the ledger lists of residents aged 60 years or more. In rural areas, there are multiple villages within a single village tract. In such cases, one of the villages was randomly selected from the village tract.

The differences between wards and village tracts involve the degree of urbanization. Urban areas are defined as wards, and rural areas are defined as village tracts or villages. Wards and village tracts sometimes co-exist within a township. In the survey, we selected only wards from townships in the Yangon region and only village tracts from among those in the Bago region, as we considered the Yangon region representative of urban areas and the Bago region as representative of rural areas.

Trained surveyors visited homes with public health nurses from each community to conduct face-to-face interviews with the study participants. In Yangon, the surveyors visited 1,083 older adults; 610 were at home. Ten were excluded due to refusing the survey $(n=6)$ or to severe dementia or being bedridden $(n=$ 4); the response rate was $98.4 \%$ in Yangon. In Bago, surveyors visited 1044 older adults; 694 were at home. Ninety-four were excluded due to severe dementia or being bedridden, thus the response rate was $86.5 \%$ in Bago. In total, six hundred people each from the Yangon (222 men and 378 women) and Bago regions (261 men and 339 women) were surveyed.

\section{Study tools}

A structured questionnaire for the face-to-face interviews was developed for this study (Additional file), following the Japan Gerontological Evaluation Study (JAGES), which is a nationwide, population-based, prospective cohort study for older community-dwelling Japanese adults [35]. The linguistic translation and validation process followed the "Linguistic Validation Manual for Health Outcome Assessments[36]. 
It was first translated into English. Thereafter, it was translated into the local language and back translated into English to ensure clarity and consistency.

We hired research staff from the Myanmar Perfect Research Company, a group that conducts epidemiological surveys in Myanmar. The interviewers were recruited from the company. Before the commencement of the actual survey, a two-day training course on the research protocol, administration of the questionnaire, and ethical concerns was conducted for the interviewers.

A small pilot study was carried out before the actual survey for face validity in Urban Health Center, Dagon township, Yangon. Participants were the older adults, age of above 60 came to the out-patient clinic in the center. We recruited the 25 respondents who were gave consent to participate in the pilot study. During the pilot study, the interviewers ensured sequence, flow, and clarity of the study. After the feedback from the interviewers, the questionnaire was revised accordingly.

The inclusion criteria were an age of $\geq 60$ years and residence in a selected ward or village tract. The exclusion criteria were being bed-ridden or having severe dementia. Severe dementia was defined as an Abbreviated Mental Test score of $\leq 6[37,38]$.

\section{Dependent variable}

We assessed happiness through the following question: "How do you rate your overall happiness level on a score of 0 for very unhappy to a score of 10 for very happy?" This question was previously validated[16, 39].

\section{Independent variables}

The wealth index, used as an objective economic indicator, was calculated from household asset items (radio, washing machine, TV, electric rice cooker, video/DVD player, air conditioner, electric fan, bicycle, refrigerator, motorcycle, computer, car/truck, store-bought furniture, microwave oven, personal music player, mobile phone, and internet) using a method described in a previous report [40]. Subjective economic status was assessed by asking the following question: "Which of the following best describes your current financial situation in light of general economic conditions?" The possible responses were (1) very difficult, (2) difficult, (3) average, (4) comfortable, and (5) very comfortable. Based on the responses, participants were categorized as "difficult or very difficult" (answering 1 or 2) or "average or higher" (answering 3 to 5).

\section{Confounding variables}

The socio-demographic characteristics of the study participants included information regarding age, sex, subjective health status (excellent/good or fair/poor), illness during the preceding year, depressive symptoms (geriatric depression scale [GDS] $=>5$ or $<5$ ), educational level (no school, monastic, some/all primary school, middle/high school or higher), residential area (the Yangon or Bago regions), marital status (married or widow/divorced/never married), living status (alone or not), social supports (giving and 
receiving emotional \& instrumental help), religion (Buddhism or other), and frequency of visits to religious facilities (less than once per week or once per week or more).

\section{Statistical analysis}

The mean happiness scores of the socio-demographic variables that were categorized as above were compared using a one-way analysis of variance test. A linear regression analysis was performed to identify the factors associated with being happy. The multivariate adjusted results were expressed as non-standardized coefficients (B) with 95\% confidence interval (CI). We used STATA 14 (StataCorp, College Station, TX, USA) to perform all statistical analyses, and the statistical significance level was set at $p<.05$.

\section{Results}

\section{Characteristics of respondents who were happy and unhappy}

Table 1 shows the happiness scores for each socio-demographic variable. For the 1,200 respondents, the mean happiness score was $6.58( \pm 2.01)$. Regarding ES, respondents with low objective ES had significantly lower happiness scores than those with middle/high objective ES (6.24 points versus 6.80 points, $p<0.001)$. Similarly, the respondents with low subjective ES had significantly lower scores than those with average or higher subjective ES (5.62 points versus 6.83 points, $p<0.001)$. For details, see Table 1.

\section{Associations between objective/subjective SES and happiness}

Low objective and subjective ES were both negatively associated with happiness, even after adjusting for the confounding variables (B: $-0.41,95 \% \mathrm{Cl}:-0.69,-0.13$; B:-0.71, $95 \% \mathrm{Cl}:-1.00,-0.42$, respectively) (Table 2). After being stratified into an urban area (Yangon) and a rural area (Bago), low objective and subjective ES were both still negatively associated with happiness in the urban and rural areas (for low objective ES in urban areas: B:-0.52, 95\% Cl: $-1.03,-0.02$, for low subjective ES in urban areas: B: $-0.50,95 \% \mathrm{Cl}:-0.96$, -0.03 ; for low objective ES in rural areas: $\mathrm{B}$ : $-0.37,95 \% \mathrm{Cl}:-0.73,-0.02$; and for low subjective ES in rural areas: $\mathrm{B}:-0.80,95 \% \mathrm{Cl}:-1.18,-0.41)$.

\section{Discussion}

To the best of our knowledge, this is the first study to investigate whether objective or subjective ES is associated with happiness using data from urban and rural areas in Myanmar. Using project data from 2018 , we found that the mean happiness score was estimated to be $6.58( \pm 2.01)$ points. Overall, the model with potential confounding factors adjusted suggested that older adults with low objective ES were more likely to have a lower happiness score than those with average or higher objective ES, and the association was similar for low subjective ES. The associations between objective or subjective ES and happiness scores remained significant in both the urban (Yangon) and rural (Bago) areas, even after they 
were stratified by region. Both objective and subjective ES had a similar impact on happiness in urban areas, while subjective ES had more than double the impact on happiness compared to objective ES in rural areas.

To compare the happiness scores among other Asian populations, we calculated the mean happiness score of the participants of the JAGES[35], which we referred to for this Myanmar study; the mean happiness score for adults aged 65 years and above was estimated to be $7.22( \pm 1.93)$ points in the JAGES study $(n=180,324)$. Although we cannot directly compare the mean happiness score in this study with that of the previous study due to differences in the sample size and the age range, the mean happiness score in Myanmar might be relatively lower than that in Japan. This might be related to Myanmar's relatively lower socioeconomic status and higher prevalence of poverty. According to the Myanmar Living Conditions Survey from 2017, one in four people perceived themselves as poor, and another $32 \%$ were just above the poverty line, facing the risk of falling into the poverty trap in the event of any adversity [41, 42]. In addition, it might be related to the relatively higher prevalence of depressive symptoms in Myanmar (22.2\%) compared with the median prevalence rate of depressive symptoms among adults aged 60 years and above around the world $(10.3 \%)[43,44]$.

In this study, low objective and subjective ES were both associated with a lower happiness score even after adjusting the confounding factors (Table 2). There is a possible reason why older adults with low objective/subjective ES were less likely to be happy than those with average/high objective/subjective ES in Myanmar. In a previous systematic review and meta-analysis, there appeared to be a consistent and statistically significant increase in the odds of cancer, angina, asthma, depression, and comorbidity prevalence when comparing low objective ES with middle/high objective ES [45, 46]. Similarly, the risk of coronary artery disease, hypertension, diabetes, and dyslipidemia was higher when comparing low and high subjective social status [47]. Consistent with previous studies, in this study, low objective/subjective ES was found to potentially affect physical health due to poverty, which is associated with a lack of public services like education, health services, access to clean water, sanitation, and clean fuel. This exacerbates the vulnerability of poor people and the perception of status differentiation, which could lead to low happiness. Although we adjusted for self-rated health, health disparities due to differences in objective/subjective ES could influence happiness in older adults in Myanmar. Even in Japan, which is considered an egalitarian society with relatively few inequalities in health, subjective ES (perceived income inequality) was negatively associated with happiness, and objective ES (income status) attenuated the association[26].

Although a previous study indicated that low subjective ES could increase stress directly or increase vulnerability to the effects of stress more than low objective ES[48], to the best of our knowledge, this is the first study to reveal that this influence is pronounced in rural areas. One of the reasons for this might be the influence of relative deprivation (RD). Previous studies offered the RD hypothesis as a possible explanation for the damaging implications of inequalities in health [49-53]. The idea behind this hypothesis is that an individual's health or health-related behavior is not only determined by that individual's own resources (such as income or educational attainment), but also by their relative position 
in reference to those resources (i.e., how much others have versus how much they have), and by the distribution of income within society $[51,53]$. Subjective ES might be more strongly linked with RD than objective ES, especially in rural areas, since rural areas tend to be small and strongly united [54,55], making it easier to see the economic situation of people in the same community. Even if older adults are objectively poor, they might feel happy if there is little RD in their society. On the other hand, it is harder for them to be happy if they have high neighborhood social cohesion and feel poorer than others in such rural areas.

Moreover, Myanmar is classified as a country with a critical shortage of health workers, which jeopardizes access to health services, resulting in poorer health status in people in hard-to-reach places[56], and healthcare disadvantages could be particularly detrimental to older adults, whose healthcare needs are high[57]. Despite ongoing changes in rural Myanmar, a considerable rural-urban gap not only in human resources (education, knowledge, and skills) but also in access to material (land, farms, and savings) and social resources (trust-based bonds) could affect residents' happiness and their psychological process of coping with chronic diseases[58]. In such an environment, it is possible that subjective ES was more likely to affect happiness than objective ES among older adults living in a rural area, although we adjusted for possible confounding variables.

The strength of this study is that it is, to the best of our knowledge, the first study to investigate happiness with a focus on ES among older adults in Myanmar. In addition, this study reported on the current situation of older adults after significant circumstantial changes in Myanmar. Some previous papers explored the sociodemographic status of older adults in Myanmar using survey data from 2012[59-62] and from the national census conducted in 2014 [63]. However, the changes due to Myanmar's democratization happened after those surveys.

The findings of this study should be interpreted within the context of several limitations. First, this analysis adopted a cross-sectional design, so causal relationships between objective/subjective ES and happiness could not be determined. We plan to employ a cohort study approach to explore any potential causality. Second, the happiness measure was based on a single item and was self-reported. Therefore, although this measure has been commonly used in previous studies and has been shown to be moderately reliable $[16,64-66]$, the results do not necessarily translate to clinical significance for psychological health. Objective multi-item measures of happiness should be considered for future studies [16]. However, the mitigation of the impact of low objective/subjective ES on happiness ( $B=-0.41$ and 0.71 , respectively) was comparable to the aggravation of the impact of low self-rated health and depressive symptoms ( $B=-0.43$ and -0.99 , respectively; data not shown), which has exceptional predictive validity with respect to mortality and morbidity [67-69]. Third, it is unknown whether these findings are generalizable beyond the Yangon and Bago regions of Myanmar. People who live in the Bago region may enjoy better access to urban areas and health facilities relative to those living in other rural areas further away from Yangon. This social epidemiological survey should be extended to include the surrounding regions and states throughout the country in the future. 
Finally, our survey sample excluded those who were bed-ridden or had severe dementia. Assuming that the happiness of those people was lower (due to their poor health) [16], happiness may have been overrated in our analysis, and our findings may not depict the whole picture of older adults in Myanmar.

In conclusion, both objective and subjective ES might influence happiness among older adults in Myanmar. However, subjective rather than objective ES has a stronger impact on happiness in rural areas. Future studies should look into the effectiveness of increasing levels of happiness through specific interventions considering regional differences. As population ageing is a growing issue in Myanmar, it is necessary to look beyond just ameliorating illnesses and implement changes that enable longevity with good physical and mental health and happiness.

\section{Abbreviations}

$\mathrm{Cl}$

Confidence interval

ES

Economic status

GDS

Geriatric depression scale

JAGES

the Japan Gerontological Evaluation Study

$\mathrm{RD}$

Relative deprivation

\section{Declarations}

\section{Ethical approval and consent to participate}

The survey protocol was reviewed and approved by the ethical review committee of the Department of Medical Research at the Ministry of Health and Sports, the Republic Union of Myanmar (Ethics/DMR/2018/038); the World Health Organization ethics committee; the ethics board at Niigata University (2018-0096); and the National Institute of Public Health in Japan (NIPH-IBRA\#12279). Written informed consent was obtained from all participants before the interviews. Voluntary participation and the right to withdraw participation at any time were assured. Individual data could not be identified from the aggregated format; thus, confidentiality was preserved. The study conformed to the principles of the Declaration of Helsinki.

\section{Consent for publication}

Not applicable

\section{Availability of data and materials}


The datasets used and anaysed during the current study are available from the corresponding author on reasonable request.

\section{Competing interests}

None declared

\section{Funding}

The research was funded by AMED (Japan Agency for Medical Research and Development), for the project titled, "Development of Health Equity Assessment Tool Based on Social Epidemiological Survey for Older Adults in Myanmar and Malaysia", Grants in aid for Scientific Research from the Japan Society for the Promotion of Science, for the project titled, "Differences in Social Capital Influence on Depression among Older People-A Comparative Study of Three Asian Countries" (19K19472), and Grants in aid for Health and Labor Administration Promotion Research Project titled 'Study on promotion of active and healthy aging in ASEAN (20BA2002)'. In addition, the World Health Organization Kobe Centre for Health Development funded the research as research to accelerate universal health coverage in light of population ageing in ASEAN countries for research titled, "Development and Validation of Questionnaire Instrument for Evaluating the Determinants of Health Status and Universal Health Coverage in Older Adults in Selected Population in Myanmar and Malaysia (WHO Kobe Centre - WKC: K18015)".

\section{Author Contributions}

Yuri Sasaki analyzed the data and produced the first draft of the manuscript. Yugo Shobugawa, Ikuma Nozaki, Daisuke Takagi, Yuiko Nagamine, Masafumi Funato, Yuki Shirakura, Yuki Chihara, Kay Thi Lwin, Poe Ei Zin, Thae Za chi Bo, Tomofumi Sone, and Hla Hla Win collected the data and revised the manuscript intensively. All authors approved the final manuscript, and Sasaki is the guarantor.

\section{Acknowledgments}

We would like to thank all the study participants and express our gratitude to Professor Than Win Nyunt, from the Department of Geriatric Medicine, Yangon General Hospital, Yangon, Myanmar; Infectious Diseases Research Centre of Niigata University members, particularly Professor Reiko Saito, and Professor Hisami Watanabe. In addition, we thank Ms. Saw Thu Nander, Mr. Yi Mynt Kyaw, and Myanmar Perfect Research team members, who were deeply involved in the project implemented to conduct the survey. We wish to express our gratitude to the Japan Gerontological Evaluation Study principle investigator, Professor Katsunori Kondo, and core members, Dr. Naoki Kondo, Dr. Jun Aida, Dr. Toshiyuki Ojima, and Dr. Masashige Saito, who provided helpful advice regarding the project; Dr. Hiroshi Murayama from the University of Tokyo, who advised the authors on the aging survey based on his professional experience; Ms. Akiko Tomita and Ms. Naoko Ito from the Japan International Cooperation Agency, who supported the conduct of the survey; Ms. Tomoko Manabe, who performed excellent secretarial support during the entire study; and Dr. Reiko Hayashi from the National Institute of Population and Social Security Research, Japan, who provided supportive advice. 


\section{References}

1. Steptoe A, Deaton A, Stone AA: Subjective wellbeing, health, and ageing. The Lancet 2015, 385(9968):640-648.

2. Radermacher WJ: Recent and future developments related to "GDP and Beyond". Review of Income and Wealth 2015, 61(1):18-24.

3. Dolan P, White MP: How Can Measures of Subjective Well-Being Be Used to Inform Public Policy? Perspectives on psychological science : a journal of the Association for Psychological Science 2007, 2(1):71-85.

4. Veenhoven R: Healthy happiness: Effects of happiness on physical health and the consequences for preventive health care. Journal of happiness studies 2008, 9(3):449-469.

5. Chei CL, Lee JM, Ma S, Malhotra R: Happy older people live longer. Age Ageing 2018, 47(6):860-866.

6. Liu B, Floud S, Pirie K, Green J, Peto R, Beral V: Does happiness itself directly affect mortality? The prospective UK Million Women Study. Lancet 2016, 387(10021):874-881.

7. Chida Y, Steptoe A: Positive psychological well-being and mortality: a quantitative review of prospective observational studies. Psychosom Med 2008, 70(7):741-756.

8. Ostir GV, Markides KS, Black SA, Goodwin JS: Emotional well-being predicts subsequent functional independence and survival. J Am Geriatr Soc 2000, 48(5):473-478.

9. Pressman SD, Cohen S: Does positive affect influence health? Psychol Bull 2005, 131(6):925-971.

10. Koopmans TA, Geleijnse JM, Zitman FG, Giltay EJ: Effects of happiness on all-cause mortality during 15 years of follow-up: The Arnhem Elderly Study. Journal of Happiness Studies 2010, 11(1):113-124.

11. Moskowitz JT, Epel ES, Acree M: Positive affect uniquely predicts lower risk of mortality in people with diabetes. Health psychology : official journal of the Division of Health Psychology, American Psychological Association 2008, 27(1s):S73-82.

12. Lawrence EM, Rogers RG, Wadsworth T: Happiness and longevity in the United States. Soc Sci Med 2015, 145:115-119.

13. Schiffrin HH, Nelson SK: Stressed and happy? Investigating the relationship between happiness and perceived stress. Journal of Happiness Studies 2010, 11(1):33-39.

14. Fredrickson BL: The value of positive emotions: The emerging science of positive psychology is coming to understand why it's good to feel good. American scientist 2003, 91(4):330-335.

15. Zhou Y, Zhou L, Fu C, Wang Y, Liu Q, Wu H, Zhang R, Zheng L: Socio-economic factors related with the subjective well-being of the rural elderly people living independently in China. International journal for equity in health 2015, 14:5.

16. Sasaki I, Kondo K, Kondo N, Aida J, Ichikawa H, Kusumi T, Sueishi N, Imanaka Y: Are pension types associated with happiness in Japanese older people?: JAGES cross-sectional study. PLoS One 2018, 13(5):e0197423. 
17. Sun S, Chen J, Johannesson M, Kind P, Burström K: Subjective Well-Being and Its Association with Subjective Health Status, Age, Sex, Region, and Socio-economic Characteristics in a Chinese Population Study. Journal of Happiness Studies 2016, 17(2):833-873.

18. Tran NLT, Wassmer RW, Lascher EL: The Health Insurance and Life Satisfaction Connection. Journal of Happiness Studies 2017, 18(2):409-426.

19. Keng S-H, Wu S-Y: Living Happily Ever After? The Effect of Taiwan's National Health Insurance on the Happiness of the Elderly. Journal of Happiness Studies 2014, 15(4):783-808.

20. Ergin I, Mandiracioglu A: Demographic and socioeconomic inequalities for self-rated health and happiness in elderly: the situation for Turkey regarding World Values Survey between 1990 and 2013. Archives of gerontology and geriatrics 2015, 61(2):224-230.

21. Kye SY, Park K: Health-related determinants of happiness in Korean adults. International journal of public health 2014, 59(5):731-738.

22. Tan JH, Abdin E, Shahwan S, Zhang Y, Sambasivam R, Vaingankar JA, Mahendran R, Chua HC, Chong SA, Subramaniam M: Happiness and Cognitive Impairment Among Older Adults: Investigating the Mediational Roles of Disability, Depression, Social Contact Frequency, and Loneliness. International journal of environmental research and public health 2019, 16(24).

23. Sakamoto R, Okumiya K, Norboo T, Tsering N, Wada T, Fujisawa M, Imai H, Nose M, Ishimoto Y, Kimura $\mathrm{Y}$ et al: Health and happiness among community-dwelling older adults in Domkhar valley, Ladakh, India. Geriatrics \& gerontology international 2017, 17(3):480-486.

24. Yiengprugsawan V, Seubsman S-a, Sleigh AC: Unhappiness and mortality: evidence from a middleincome Southeast Asian setting. BioPsychoSocial Medicine 2014, 8(1):18.

25. Hsu HC, Chang WC, Chong YS, An JS: Happiness and social determinants across age cohorts in Taiwan. Journal of health psychology 2016, 21(9):1828-1839.

26. Oshio T, Urakawa K: The Association Between Perceived Income Inequality and Subjective Wellbeing: Evidence from a Social Survey in Japan. Social Indicators Research 2014, 116(3):755-770.

27. Tay L, Kuykendall L: Promoting happiness: the malleability of individual and societal subjective wellbeing. International journal of psychology : Journal international de psychologie 2013, 48(3):159176.

28. Lu L, Kao SF: Striving for Positive Aging Among Chinese Older People: Effects of Life Stress and Control Beliefs in a Longitudinal Study. International journal of aging \& human development 2018, 86(4):382-400.

29. Adesanya AO, Rojas BM, Darboe A, Beogo I: Socioeconomic differential in self-assessment of health and happiness in 5 African countries: Finding from World Value Survey. PLoS One 2017, 12(11):e0188281.

30. Amorim SM, Franca L, Valentini F: Predictors of happiness among retired from urban and rural areas in Brazil. Psicologia, reflexao e critica : revista semestral do Departamento de Psicologia da UFRGS 2017, 30(1):2. 
31. Deng Y, Paul DR: The Relationships between depressive symptoms, functional health status, physical activity, and the availability of recreational facilities: a rural-urban comparison in middle-aged and older Chinese adults. International journal of behavioral medicine 2018, 25(3):322-330.

32. Ageing population in Myanmar: Trends in ageing and health Myanmar [https://ageingasia.org/ageing-population-myanmar/]

33. Htet AS, Bjertness MB, Sherpa LY, Kjøllesdal MK, Oo WM, Meyer HE, Stigum H, Bjertness E: Urban-rural differences in the prevalence of non-communicable diseases risk factors among 25-74 years old citizens in Yangon Region, Myanmar: a cross sectional study. BMC Public Health 2016, 16(1):1225.

34. Selth A: Modern Burma studies: a survey of the field. Modern Asian Studies 2010, 44(2):401-440.

35. Japan Gerontological Evaluation Study [https://www.jages.net/?_layoutmode=off\&lang=english]

36. Acquadro C, Conway K, Giroudet C, Mear I: Linguistic validation manual for health outcome assessments: Mapi Institute; 2012.

37. Jitapunkul S, Pillay I, Ebrahim S: The abbreviated mental test: its use and validity. Age Ageing 1991, 20(5):332-336.

38. MacKenzie DM, Copp P, Shaw RJ, Goodwin GM: Brief cognitive screening of the elderly: a comparison of the Mini-Mental State Examination (MMSE), Abbreviated Mental Test (AMT) and Mental Status Questionnaire (MSQ). Psychological medicine 1996, 26(2):427-430.

39. Matsubayashi K, Kimura S, Iwasaki T, Okumiya S, Hamada T, Fujisawa M, Takeuchi K, Kawamoto A, Ozawa T: [Evaluation of subjective happiness in the elderly using a visual analogue scale of happiness in correlation with depression scale]. Nihon Ronen Igakkai zasshi Japanese journal of geriatrics 1992, 29(11):811-816.

40. Filmer D, Pritchett LH: Estimating wealth effects without expenditure data-or tears: an application to educational enrollments in states of India. Demography 2001, 38(1):115-132.

41. Myanmar's Central Statistical Organization of the Ministry of Planning Fal, The World Bank, United Nations Development Programme: Myanmar Living Conditions Survey 2017 : Socio-Economic Report In.; 2020.

42. Choragudi U: Surveys shows inequality a serious problem in Myanmar. In: Mizzima Yangon, Myanmar; 2020.

43. Barua A, Ghosh MK, Kar N, Basilio MA: Prevalence of depressive disorders in the elderly. Annals of Saudi medicine 2011, 31(6):620-624.

44. Wada T: Depression of Community-Dwelling Elderly in Three Asian Countries: Myanmar, Indonesia, and Japan. Kyoto Working Papers on Area Studies: G-COE Series 2009(18):1-11.

45. Williams J, Allen L, Wickramasinghe K, Mikkelsen B, Roberts N, Townsend N: A systematic review of associations between non-communicable diseases and socioeconomic status within low- and lowermiddle-income countries. Journal of global health 2018, 8(2):020409.

46. Hosseinpoor AR, Bergen N, Mendis S, Harper S, Verdes E, Kunst A, Chatterji S: Socioeconomic inequality in the prevalence of noncommunicable diseases in low- and middle-income countries: 
Results from the World Health Survey. BMC Public Health 2012, 12(1):474.

47. Tang KL, Rashid R, Godley J, Ghali WA: Association between subjective social status and cardiovascular disease and cardiovascular risk factors: a systematic review and meta-analysis. $B M J$ Open 2016, 6(3):e010137.

48. Adler NE, Epel ES, Castellazzo G, Ickovics JR: Relationship of subjective and objective social status with psychological and physiological functioning: Preliminary data in healthy, White women. Health psychology 2000, 19(6):586.

49. Adjaye-Gbewonyo K, Kawachi I: Use of the Yitzhaki Index as a test of relative deprivation for health outcomes: a review of recent literature. Social science \& medicine 2012, 75(1):129-137.

50. Wilkinson RG: Socioeconomic determinants of health: Health inequalities: relative or absolute material standards? BMJ (Clinical research ed) 1997, 314(7080):591.

51. Caner A, Yigit YC: Relative deprivation and its association with health indicators: Lower inequality may not improve health. SSM - population health 2019, 7:100381.

52. Smith HJ, Pettigrew TF, Pippin GM, Bialosiewicz S: Relative deprivation: a theoretical and metaanalytic review. Personality and social psychology review : an official journal of the Society for Personality and Social Psychology, Inc 2012, 16(3):203-232.

53. Kawachi I, Kennedy BP: Income inequality and health: pathways and mechanisms. Health services research 1999, 34(1 Pt 2):215-227.

54. Ziersch AM, Baum F, Darmawan IGN, Kavanagh AM, Bentley RJ: Social capital and health in rural and urban communities in South Australia. Australian and New Zealand journal of public health 2009, 33(1):7-16.

55. Riva M, Bambra C, Curtis S, Gauvin L: Collective resources or local social inequalities? Examining the social determinants of mental health in rural areas. European journal of public health 2011, 21(2):197-203.

56. Sommanustweechai A, Putthasri W, Nwe ML, Aung ST, Theint MM, Tangcharoensathien V, Wynn SS: Community health worker in hard-to-reach rural areas of Myanmar: filling primary health care service gaps. Human resources for health 2016, 14(1):64.

57. Li LW, Liu J, Xu H, Zhang Z: Understanding Rural-Urban Differences in Depressive Symptoms Among Older Adults in China. Journal of aging and health 2016, 28(2):341-362.

58. Ziarko M, Mojs E, Kaczmarek LD, Warchol-Biedermann K, Malak R, Lisinski P, Samborski W: Do urban and rural residents living in Poland differ in their ways of coping with chronic diseases? European review for medical and pharmacological sciences 2015, 19(22):4227-4234.

59. Knodel J: The situation of older persons in Myanmar: results from the 2012 survey of older persons: HelpAge International; 2013.

60. Teerawichitchainan B, Knodel J: Economic Status and Old-Age Health in Poverty-Stricken Myanmar. Journal of aging and health 2015, 27(8):1462-1484.

61. Knodel J, Teerawichitchainan B: Aging in Myanmar. The Gerontologist 2017. 
62. Teerawichitchainan B, Knodel J: Long-Term Care Needs in the Context of Poverty and Population Aging: the Case of Older Persons in Myanmar. Journal of cross-cultural gerontology 2018, 33(2):143162.

63. Spoorenberg T: Provisional results of the $\mathbf{2 0 1 4}$ census of Myanmar: The surprise that wasn't. Asian Population Studies 2015, 11(1):4-6.

64. Krueger AB, Schkade DA: The reliability of subjective well-being measures. Journal of public economics 2008, 92(8-9):1833-1845.

65. Lee Y, Hofferth SL, Flood SM, Fisher K: Reliability, Validity, and Variability of the Subjective Well-Being Questions in the 2010 American Time Use Survey. Soc Indic Res 2016, 126(3):1355-1373.

66. Diener E, Wirtz D, Tov W, Kim-Prieto C, Choi D-w, Oishi S, Biswas-Diener R: New well-being measures: Short scales to assess flourishing and positive and negative feelings. Social indicators research 2010, 97(2):143-156.

67. Schnittker J, Bacak V: The increasing predictive validity of self-rated health. PloS one 2014, 9(1).

68. Latham K, Peek CW: Self-Rated Health and Morbidity Onset Among Late Midlife U.S. Adults. The Journals of Gerontology: Series B 2012, 68(1):107-116.

69. Pan A, Sun Q, Okereke Ol, Rexrode KM, Hu FB: Depression and risk of stroke morbidity and mortality: a meta-analysis and systematic review. Jama 2011, 306(11):1241-1249.

\section{Tables}




\begin{tabular}{|c|c|c|c|c|c|}
\hline & & $\mathrm{N}$ & Mean & $\pm S D$ & $\mathrm{p}$ value \\
\hline Happiness score & & 1,200 & 6.58 & 2.01 & \\
\hline Objective SES & Middle/High & 718 & 6.80 & 1.88 & $<0.001$ \\
\hline (wealth index) & Low & 480 & 6.24 & 2.14 & \\
\hline Subjective SES & Average or more & 953 & 6.83 & 1.89 & $<0.001$ \\
\hline (self-rated economic status) & Difficult/Very difficult & 247 & 5.62 & 2.14 & \\
\hline \multirow[t]{2}{*}{ Sex } & Male & 483 & 6.86 & 2.00 & $<0.001$ \\
\hline & Female & 717 & 6.38 & 2.02 & \\
\hline \multirow[t]{3}{*}{ Age } & $60-69$ & 670 & 6.61 & 2.00 & 0.25 \\
\hline & $70-79$ & 380 & 6.61 & 2.04 & \\
\hline & $80+$ & 150 & 6.32 & 2.06 & \\
\hline \multirow[t]{2}{*}{ Subjective health status } & Excellent/Good & 354 & 7.10 & 1.89 & $<0.001$ \\
\hline & Fair/Poor & 846 & 6.36 & 2.01 & \\
\hline No & 582 & 6.75 & 2.08 & $<0.01$ & \\
\hline Yes & 615 & 6.41 & 1.92 & & \\
\hline \multirow[t]{2}{*}{ Depressive symptoms } & GDS $<5$ & 921 & 6.89 & 1.89 & $<0.001$ \\
\hline & GDS $>=5$ & 265 & 5.48 & 2.01 & \\
\hline \multirow[t]{3}{*}{ Education } & No school/Monastic & 396 & 6.27 & 2.00 & $<0.001$ \\
\hline & Some/Finished primary & 417 & 6.55 & 2.06 & \\
\hline & Middle school or higher & 387 & 6.92 & 1.91 & \\
\hline \multirow[t]{2}{*}{ Region } & Yangon & 600 & 6.71 & 1.86 & $<0.05$ \\
\hline & Bago & 600 & 6.45 & 2.13 & \\
\hline \multirow[t]{2}{*}{ Marital status } & Married & 642 & 6.77 & 1.93 & $<0.001$ \\
\hline & Widow/Divorced/Never & 558 & 6.35 & 2.07 & \\
\hline \multirow[t]{2}{*}{ Living status } & Alone & 68 & 6.04 & 2.45 & $<0.05$ \\
\hline & Not alone & 1132 & 6.61 & 1.97 & \\
\hline \multicolumn{6}{|l|}{ Social Support } \\
\hline Receiving emotional support & No & 176 & 6.60 & 2.14 & 0.85 \\
\hline
\end{tabular}




\begin{tabular}{|c|c|c|c|c|c|}
\hline & Yes & 1024 & 6.57 & 1.98 & \\
\hline \multirow[t]{2}{*}{ Providing emotional support } & No & 196 & 6.54 & 2.13 & 0.78 \\
\hline & Yes & 1004 & 6.58 & 1.98 & \\
\hline \multirow[t]{2}{*}{ Receiving instrumental support } & No & 27 & 6.11 & 2.24 & 0.22 \\
\hline & Yes & 1173 & 6.59 & 2.00 & \\
\hline \multirow[t]{2}{*}{ Providing instrumental support } & No & 268 & 6.57 & 2.15 & 0.98 \\
\hline & Yes & 932 & 6.58 & 1.96 & \\
\hline \multirow[t]{2}{*}{ Religion } & Buddhism & 1147 & 6.57 & 1.99 & 0.47 \\
\hline & Other & 53 & 6.77 & 2.32 & \\
\hline \multirow[t]{2}{*}{ Frequency of religious visits } & Less than once per week & 617 & 6.40 & 1.99 & $<0.05$ \\
\hline & Once per week or more & 583 & 6.76 & 2.01 & \\
\hline
\end{tabular}


Table2. Multivariate adjusted association between happiness and objective/subjective socioeconomic status among the older adults in Myanmar

$\begin{array}{lllll}\text { Happiness } & \text { B } & \text { SE } & 95 \% \mathrm{Cl} & \begin{array}{l}\text { P- } \\ \text { value }\end{array}\end{array}$

\section{$\mathrm{n}=1,182$ (Yangon \& Bago)}

Objective SES

Middle/High

(wealth index)

Low

$-0.41$

0.14

$-0.69$

$-0.13$

0.01

Subjective SES

Average or more

(self-rated economic status)

Difficult/Very difficult

$-0.71$

$\begin{array}{llll}0.15 & -1.00 & -0.42 & 0.00\end{array}$

Adjusted R-squared $=0.14$

\section{$\mathrm{n}=591$ (Yangon)}

Objective SES

Middle/High

(wealth index)

Low

$-0.52$

0.26

$-1.03$

$-0.02$

0.04

Subjective SES

Average or more

(self-rated economic status)

Difficult/Very difficult

$-0.50$

0.24

$-0.96$

$-0.03 \quad 0.04$

Adjusted R-squared $=0.09$

\section{$\mathrm{n}=591$ (Bago)}

Objective SES

Middle/High

(wealth index)

Low

$-0.37$

0.18

$-0.73$

$-0.02$

0.04

Subjective SES

Average or more

(self-rated economic status)

Difficult/Very difficult

$-0.80$

0.20

$-1.18 \quad-0.41$

0.00

Cl: Confidence Interval; GDS: Geriatric Depression Scale; SE:

Standard Error; SES: Socioeconomic Status

Adjusted R-squared $=0.18$

Adjusted for age, sex, subjective health, illness during preceding year, depressive symptoms, education, region, marital status, living status, social supports, religion, frequency of religious visits

\section{Supplementary Files}

This is a list of supplementary files associated with this preprint. Click to download.

- Additionalfile.pdf 